\title{
2
}

\section{Rediscovering management: analysis and synthesis}

An underlying theme in the previous chapter is that public management's disciplinary identity isn't what it needs to be. As a mechanism to define discipline identity, this chapter starts off by making an historical turn. It investigates paths along which ideas have developed: specifically, ideas about professional disciplines, management, design, and public management.

Just a few years ago I came across an historical narrative about North American business schools in the post-World War II period, by Mie Augier and James G. March. ${ }^{1}$ This eye-opening book showed that fissures in the management field are deeply evident in its North American history, with the sharpest lines drawn between the pragmatist tradition represented by Harvard Business School (HBS) and the "modern management school." The ideas of the modern management school took concrete form in the 1950s, particularly at Carnegie Institute of Technology's Graduate School of Industrial Administration (GSIA), more than 25 years after the HBS approach had settled into a pattern. Augier and March showed that the institutional forerunner of the modern American management school was the modern American medical school, pioneered in the 1910s, at Johns Hopkins University. In commenting on their narrative historical account, Augier and March argue that traces of this episode in the history of management schools - including the intellectual and institutional rivalry between HBS and GSIA - can still be discerned.

This history matters for public management. It matters in a general way because fissures in the management field have shown up as battle-lines in discussions of public management. As this chapter will show, sharp battle-lines came to be drawn, once an approach to public management had taken clear form in U.S. public policy schools, most notably at Harvard's Kennedy School of Government. The person who drew those battle-lines was Lawrence Lynn, ${ }^{2}$ by that time a professor at the University of Chicago. Lynn critically opposed ideas identified institutionally with Harvard Kennedy School, where he had previously taught. As made plain by the end of his 1996 book, Lynn's own views, by the time he was at Chicago, carried a strong resemblance to those of the modern management school. Thus, the battle-lines that Lynn drew look similar to what Augier and March found had been very much true of the field of management schools decades earlier.

Going back to the management school history will help put public manage- 
ment in perspective (in part because these management disciplines are not historically independent). Herbert A. Simon plays a part in this story. While serving as a professor at Carnegie, Simon developed his now hugely influential ideas about the character of problem-solving, initially as a critical response to what became the mainstream view of the management discipline at GSIA, patterned on the modern medical school. But Simon eventually left GSIA; and his views about designing, as a distinctive idea about problem-solving, took form later, becoming better-known with successive editions of his Sciences of the Artificial. ${ }^{3}$ However, Simon didn't come up with a fully formed idea of management as a design-oriented professional discipline. The need for one has been discussed in the management field overall and in a couple of its sub-fields. ${ }^{4}$ Nevertheless, I would contend that no such idea really yet exists in substance.

This situation is perhaps unsettling. The public management discipline has usually talked about itself as if the key question requiring lucid discussion is public versus private management. The underlying assumption is that ideas about the management discipline are monolithic, that its main debates as a discipline are settled. This assumption might be convenient, but, as Augier and March's book implies, it's not valid.

This chapter analyzes and then synthesizes two approaches to theorizing management, one being Harvard-esque (hereafter, $\mathrm{H}$ ), with the other being Simon-esque (hereafter, S). The chosen primary bibliographic source for $\mathrm{H}$ is one about public management. Specifically, it's Creating Public Value: Strategic Management in Government. ${ }^{5}$ Its author, Mark H. Moore, did his doctorate at Harvard's Kennedy School of Government in the 1970s and then served as a professor at Harvard, based in that school, for nearly 40 years. Moore engaged fully with Harvard Business School (HBS) theorizations of business enterprises. Like a designer, Moore used the ideas that he came to understand deeply as precedents in coming up with a synthesis that would be suitable for public management. While Moore makes reference to his synthesis' precedents, his text didn't provide an extensive account of them.

Let me now turn to explaining the use of Simon's Sciences of the Artificial as a basis for identifying $S$. That volume contains Simon's most well-known theorization of problem-solving; specifically, Chapter 5 is the locus classicus of this theorizing. This discussion isn't presented as being specifically about management; the chapter's primary audience was professors of engineering. The reason we can be confident that Chapter 5 is a theorization of management is due to Augier and March's narrative historical account, which explained that Simon's approach to management as problem-solving was developed during his earlier period at Carnegie's business school, when he was working out an alternative to mainstream ideas within the "modern management school." 


\section{The Harvard-esque tradition as exemplified by creating public value}

As I proceed, I will assume passing familiarity with Moore's book, by which I mean some of its ideas stuck with you, but you certainly wouldn't want to be called upon out of the blue to make a well-structured presentation about it.

Taking up first things first, you will recall the initial presentation of Moore's theorization of public management involved narrating a fictional case where the Town Librarian verbalized her thinking about whether and how to take action in the face of a change in the library facility's usage patterns: specifically, in the mid-afternoon period, the library's public rooms filled up with schoolage residents of the town. This population of users was known as latchkey children: going to the library was a preferred alternative to spending after-school hours at home, with a factor being the absence of adult relatives during daytime hours. The Town Librarian and Latchkey Children case served Moore's expositional purposes for three reasons. First, the Town Library exemplified a key concept in his theory, which Moore labeled as the "public organization." Second, the Town Librarian exemplified a pivotal concept in Moore's theory, labeled as the "public manager." Third, the Town Librarian's response to the change in pattern in Town Library usage exemplified a further key concept in his theory: "strategic public management." Let's examine these ideas.

In doing this, you need to keep telling yourself that Moore is using this case discussion to theorize public management practice. It may seem odd to theorize through a case discussion, but there's a long tradition behind that. If you're going to treat Moore's discussion of this case as theorization, then you will have to look for the structure of ideas. In order to do that it helps to know something about the ideas about management that he draws upon as precedents.

As a point of entry let's take the idea of a public organization. Ask yourself, is this term being presented as a way to classify organizations? If Moore were developing a descriptive or, what is the same, a positive theory of organizations, then the idea of public organization would sensibly be conceived as a category. However, Moore didn't develop a positive theory of organizations: he developed a purposive theory of public management. In such a theory, "public organization" isn't a category: it's an idea about a kind of purposeful phenomenon. So, let's go forward on the basis that, in Moore's theory of public management, the term "public organization" plays the role of the kind of purposeful phenomenon with which his theory is concerned.

If we choose to see Moore's theory as a purposive theory and, specifically, interpret the term "public organization" as being the purposeful phenomenon within the theory, then we can follow standard steps to clarify the theory further. If a public organization is the purposeful phenomenon in Moore's theory, then Moore's theory has to say what intent is effectuated by public organizations. So, what is the specific concept within Moore's purposive theory that plays the role of public organizations' intent? This is not meant to be a demanding question. If you glance at the cover of Moore's book, you can't miss it. The role of "intent" in 
Moore's purposive theory is played by the three words that form the main title of the book.

If you stare at the overall book title, you might contemplate the relation between the main title (i.e., creating public value) and the sub-title (i.e., strategic management in government). There's not much information in the grammatical symbol - a colon - that sits between the two parts of the title. So we have to guess, while keeping in mind that Moore's theory is a purposive theory of public organizations, for use in the professional practice of public management.

In purposive theories like Moore's, professional practice consists, in part, in using theories of the purposeful phenomena with which their practice is concerned (e.g., public organizations), to channel a practitioner's imagination and deliberative reasoning. The outcome of such cerebral activity is effectively a plan for what such practitioners are going to think and do as they further engage with the situation involving the purposeful phenomenon at hand (e.g., public organizations) in whatever capacity they hold (e.g., managerial roles in public organizations). I'd say that "strategic management in government" is a reference to the professional practice of public management. More precisely, "strategic management in government" is a reference to the sum-total of ideas in Moore's theory that are meant to channel a practitioner's imagination and deliberative reasoning.

For ease of recall and reference, I formalize this discussion of Moore's purposive theory in the following way:

1. Public organizations effectuate public value creation. ${ }^{6}$

2. Strategic public management ideas channel practitioners' imaginative and deliberative reasoning about public organizations; such activity eventuates in practitioners' plans for further professional activity. ${ }^{7}$

If you're familiar with Moore's book, you may understandably react to this involved discussion and its formalization by asking: why not just say public managers create public value? After all, that's one of the most memorable ideas about Moore's book. You can guess my answer: the idea that public managers create public value is like a tag-line, bumper sticker, or sound-bite: it is meant to be a sticky message. The line works because it expresses some of the core ideas of Moore's purposive theory in an exceedingly compact way. That's helpful in establishing Moore's book as a reference, which is a good thing. But, on its own, the idea that public managers create public value isn't that helpful to public management practice, let alone developing public management as a professional discipline.

For professional practice, the most useful role that the line "public mangers create public value" can play is in indexing Moore's theory in a practitioner's memory system; in this role, referring to public managers as public-value creators can be used to activate the neural networks that, in turn, channel a practitioner's imaginative thinking and deliberative reasoning about actual public organizations. ${ }^{8}$ For that scenario to happen, however, a practitioner's neural networks have to reflect Moore's theory, in its expert rather than sound-bite 
version. How can such networks come to be formed in the mind? It requires a learning activity, ${ }^{9}$ one in which concept acquisition is channeled by reference to a well-structured, purposive theory.

Having made the case for using ideas about purposive theorizing in uncovering the expert version of Moore's theory of public management, let's now return to the task of stating what it is, going into more substantive depth. A starting point is to examine the earlier, formalized idea that public organizations effectuate public value creation. Consider the case of the Town Librarian and Latchkey Children. No doubt we learn of aspects of the Town Library, considered as an organization, such as the fact that the town librarian's formal role is located at the apex of the library's organization structure and that the organization's staff identifies themselves professionally as librarians. But much of the discussion of the case is about the library facility's public spaces, usage patterns by clientele group, and accessing library holdings. This information doesn't clash with the idea that the case is about a public organization, provided the idea of technology is a property of the idea of organization. Nevertheless, there's another concept that gives meaning to these otherwise disparate observations: it's the program results-chain. The library's public spaces and holdings are inputs; usage of the library's public spaces by clients and accessing its holdings are activities; information transferred from accessible library resources to the library users' internal and external memory systems are outputs. On the basis of this case discussion, then, we can see that Moore's concept of public organization includes two ideas: an organization (with its role structure, personnel, culture, contractual partners, and technology) and a program (with the inputs, activities, and outputs of a public service operation).

As we think about the structure of Moore's theory, we might want to ask: is there any point making a distinction between the idea of "organization" and the idea of "program"? I think there is. My interpretation is that in Moore's theory of public management, program results chains provide relatively fine-grained information about how any given public organization effectuates public value creation, when that information is compared with the organization's role structures, personnel, contractual partners, and technology. That point - and the conceptual distinction between organization and program underneath it - becomes plainly evident if you manage to work your way through Moore's discussion in Chapter 2 of the illustrative case of the municipal sanitation department and its program of picking up the garbage.

The organization/program distinction has a practical import, within Moore's theory. Recall the statement that, "strategic public management ideas channel practitioners' imaginative and deliberative reasoning about public organizations; such activity eventuates in practitioners' plans for further professional activity." The implication is that specific ideas about programs and public service operations have a role to play in channeling practitioners' imaginative and deliberative reasoning, a role that is distinct from ideas about organizations. (Thinking about public management as a professional discipline, a different sort of implication is that professional knowledge about public management and program planning should go hand-in-hand.) 
We now face a terminological problem. "Public organizations" is a term that means two related things. An organization and a program/public service operation. You could work hard to remember that "public organizations" includes a program/public service operation, in Moore's theory. That's fine, but there may be a better alternative, for which there is a long-standing precedent in management theory. It's the concept of an enterprise, which was introduced in the oldest modern theorization of management, by Henri Fayol, written in French and translated years later into English. In Fayol's theory, an enterprise is like an organism that, to survive and thrive, performs functions, which he listed as the technical, commercial, financial, accounting, security, and management functions. ${ }^{10}$ The organization - which his text sometimes referred to as "the body social" - is a structure that effectuates the performance of these functions. How does the idea of a program/public service operation in Moore's theory relate to this scheme? It's the public sector analogue to performing an enterprise's technical and commercial functions. How do organizations in Moore's theory relate to this scheme? They effectuate the performance of all of these enterprise functions, and they consist in a "body social." So, my suggestion is that we recruit the concept of enterprise from Fayol's theorization of management to solve a terminological problem. If the term "enterprise" in Fayol's theory is substituted for the term "public organization" in Moore's theory, then Moore's theory could be understood as being about two aspects of enterprises: organizations and programs. (There would also be a symmetry to the contemporary management literature, where the idea of an enterprise covers both an organization governed as a company and a business operated by a company.)

While the inclusion of "enterprise" in Moore's theory would solve a terminological problem, it might raise a labeling problem. Moore surely was aware of this labeling problem when he chose to use the term "public organizations." As a matter of history, those who translated Fayol's book from French to English were involved in public administration; they translated Fayol's term "entreprise" into organization; they had their audience in mind. Moore was being conservative in his labeling. In what follows, I'll use the word "enterprise," because I want to avoid the terminological problem: but if it creates labeling problems for you, please feel free to relabel the idea as public organization, like Moore, or go for something different but slightly less corporate, like "public venture."

Having discussed public organizations, we can turn to the idea of a public manager. Here's a question for you: does Moore introduce this concept as a category to classify actors, roles, or statuses within government? By now you probably will guess that my answer is no. "Public manager" is a concept within a purposive theory of public management. Concepts within purposive theories aren't classificatory categories. Does that mean that Moore says nothing about the "properties" of the concept of public managers? No, it just means that when Moore is presenting his theory of public management, public managers isn't a classificatory category.

To see the difference, let's take a quick look at the meaning of "public managers" as a category. A key property of public managers is that they are biological individuals; another key property is that they work within the institution of 
government. The question then becomes how the concept of public managers is differentiated from the concept of biological individuals working within the institution of government. One differentiating property is that public managers work within public bureaucracies; they are not legislators or judges. That is about all one can say about public managers, by listing this category's defining properties.

One can say more by listing typical properties. For Moore, a typical property is that public managers are appointed to their jobs; to be a public manager and elected is atypical, as might be the case with U.S. jurisdictions with "long ballots," where, for example, a state-level secretary of state or attorney general would gain office through elections. How a public manager becomes appointed to their jobs is not a property of the concept of a public manager; for this reason, referring to public managers as bureaucrats would be terminologically incorrect. One could perhaps say more: for example, that a typical property of public managers is that their positions are managerial, where this property is a constellation of more specific properties, such as holding of grant of (conditional) authority in relation to coordinate authorities or hierarchical subordinates. So, now if you were asked to define what a public manager is, you'd know what to say. It's a category with defining and typical properties (as listed), within which can fit some atypical cases (such as elected public managers).

At the risk of pointing out the obvious, the idea of a public manager within Moore's purposive theory of public management is related to the idea of a manager in purposive theories of business management. By analyzing this relationship, we will get on the road toward understanding the idea of a public manager. Not only that, we will come to see how Moore's theory is Harvard-esque, which will prepare the ground for later discussions.

In analyzing the relationship, consider that Moore's book was published in 1995 , following a gestation period of about a decade. The book's content was developed during a period when Moore was active in developing curriculum for executive programs for public officials, with the collaboration of a few Harvard Business School professors, identified with the area of general management and business policy. In form, the curriculum design was modeled on executive and MBA education, as it was practiced at HBS and at other institutions that had followed its lead. The form included case studies of administrative situations as they had been shaped by earlier events. Classroom discussion focused on issues posed by such a situation, as they would be formulated by specific actors caught up in it, in accord with their organizational role. Participant discussions were facilitated, guided, and summed-up by the case teacher. While the form of the curriculum design was a replica of teaching at Harvard Business School, the content was meant to be specific to public management. Moore's book is the product of this history.

Case method teaching of business management was established at HBS in the 1920s; its precedent was case method teaching of legal practice, which had come to be established at Harvard Law School during the previous 25 years or so. ${ }^{11}$ It stands to reason that basic ideas about professional practice exhibited in case teaching in the Law School were absorbed into the teaching of business management. And what ideas were those? One of those ideas was casuistry. 
Casuistry is a form of practice employed to reach and explain decisions in life. The basic idea is that, even when there's consensus on principles of what's right to do, there's still lots of room for disagreement about what's right to do, in particular circumstances. Room for disagreement is particularly wide when circumstances throw up a dilemma, as circumstances often do. When that happens, there's no alternative to leaving it to individuals to come to their own conclusions - and then explain them. A role for casuistry is to develop any given individual's judgmental capacity - which means being able to arrive at and explain difficult decisions.

The method for developing such capacity is to work through cases, under instruction: in particular, to present one's holding as to what is, or was, the right thing to do; to provide a rationale for the holding, consistent with the moral tradition employing the casuistical practice; and then to deal with objections and rebuttals. (If you want to read a more expert and fuller account of casuistry, see, Jonsen and Toulmin ${ }^{12}$ or make do with Wikipedia.)

The parallels between casuistry and case-method legal instruction are doubtlessly strong. You can easily imagine a case teacher asking whether you agree or disagree with a judge's holding in a case, and also whether you agree or disagree with the opinion rationalizing the judge's holding.

What about parallels between casuistry and case-method management instruction? A strong parallel is that management instruction trains judgment, using similar methods. The student has to work through cases, arriving at decisions (holdings) and explaining their rationale; lots of cases. Some parallels are not so straightforwardly neat. In casuistry, individuals need to explain their "holdings" to fellow members of the same moral tradition; in management, individuals need to explain their "holdings" to fellow members of the same professional practice. In casuistry, the issues are about dilemmas that arise because of incompatible moral principles; in management, issues that aren't easy to resolve for all sorts of reasons, including goal ambiguity, unclear technology, uncertainty, and organizational politics. Accordingly, it seems sound to conclude that professional practice is theorized in the Harvard tradition as involving "judgment" in arriving at decisions and "argumentation" in support of them, whatever else may be true of it.

This point may seem tediously made, but let me remind you that casuistry is not a property of all theorizations of management as a professional practice. It is Harvard-esque. For the modern management school, casuistry is not a guiding idea: its guiding idea - inspired by modern medicine - was to skillfully apply theory, or theory-based tools, to the issue at hand, to choose the best option for policy or action.

So, let's pick up the discussion of Moore, where we left off. Look at how he presented the case of the Town Librarian. Moore tracks the librarian's hypothetical reasoning toward a judgment about whether the Town Library's existing program/public service operation should be preserved or, instead, modified. To get a finer picture of Moore's idea of professional practice, we need to observe that a judgment as to whether to preserve or modify a public organization's program/public service operation is conditioned by a certain kind of instruction. 
Specifically, this kind of instruction involves the use of a purposive theory of public management, according to which public organizations effectuate public value creation. This purposive theory doesn't determine the issue of whether to preserve or modify a public organization's program/public service operation: but, given the case facts, it would certainly incline a public manager against a decision in favor of preserving the status quo.

The Town Librarian and Latchkey Children case illustrates how Moore's theory of public management "works." Think of this theory as a functioningwhole, for which a serviceable but distant analogue is a machine - a simple one, with only two components. One machine-component is a purposive theory of public organizations; the other is a purposive theory of an individual's professional activity. In this simple machine, the two components are coupled, in that its purposive theory of public organizations serves as a reference point for an individual practitioner's thinking as it moves toward practical conclusions and, as well, as an idiom with which to formulate explanations for such conclusions, to be presented to fellow professional practitioners. How does this simple machine work? That's theorized in terms of how judgment works (which is to say, mainly in terms of philosophical theories of mind, rather than in terms of science of cognition), and in terms of how arguments persuade (which is to say, mainly in terms of rhetoric).

So, to restate the question that has now been discussed at some length, how is the idea of a public manager within Moore's purposive theory of public management related to the idea of a manager in purposive theories of business management? Based on what has been said so far, there's similarity in the main lines of theorization, in that professional activity is theorized along casuistical lines and as the "tradition" within which judgment and explanation flow is a purposive theory of a variant-form of enterprise. Alongside similarity is difference. The difference is in the specifics of the tradition: Moore's purposive theory of public organizations is not a replica of the purposive theory of business management; it is developed on the basis of a theorization of public programs and public institutions (as we shall see specifically in Chapter 4).

Having examined "public organizations" and "public managers," we're now at a stage where we can attempt to make sense of the third concept in Moore's purposive theory: strategic public management. As before, I ask - is this term a classificatory category? Of course not - how could it be? If it's not a classificatory category, then its meaning comes from how strategic public management relates to other ideas that we've been talking through, such as a purposive theory of public organizations. It's not exactly the same idea, because strategic public management theorizes public managers' professional activity, not just the effectuation of public value creation by public organizations. Strategic public management is not exactly the same idea as casuistical professional activity, either. If strategic public management were devoid of a purposive theory of public organizations, it would be oddly empty of substance, and it would be alien to the Harvard-esque tradition of management theorizing. So how should this problem of reference be solved? I would propose that we use "strategic public management" to refer to "the machine": a purposive theory of public management, consisting in a 
purposive theory of public organizations, coupled with a purposive theory of professional activity.

Now, let's solve another problem: labeling and presentation. For our intramural discussion, we can use the term "purposive theory." But it's not common. If you Google its word frequency, you can't even find it. If you Google the term, you'll find that it has had a meaning in the professional discipline of law, but not elsewhere. In extramural discussions, you might instead refer to strategic public management as a theory of professional practice, one that is specifically coupled with a theory of public organizations as effectuators of public value creation.

You may have noticed that the term "public managers" has slowly disappeared from the text, whereas "professional practitioners" has come to be used in its place. That's intentional, and I wish to explain why, in brief. It's a solution to a problem that I run into as a teacher of public management: it's devilishly hard to get students to read Moore's text with any depth. I attribute this problem, in part, to their understandable lack of familiarity with purposive theorizing involving both enterprises and professional activity. This pattern is prevalent among political scientists; I reckon a contributing cause is that analyzing "public managers" as a classificatory category falls well within their comfort zone. They fix their attention on what I think belongs in the background; what I want to see fixed upon escapes their grasp. From this standpoint, just reducing exposure to the term "public managers" should help.

There's another problem: Moore's purposive theory of professional practice is relevant to more actors than those who match the "definitional" and "typical" properties of public managers, in Moore's discussion of that matter. It's truly relevant to anyone who's engaged in professional activity involving public organizations, while concerned to effectuate public value creation as they do so. These actors might be staff executives; they might be government auditors; they might be consultants. The list goes on.

The term "professional practitioners" is a good substitute for "public managers." It's not an obscure term, like casuistry, or a high-register one, like effectuate. It's garden-variety. In fact, "professional practitioners" is the term Herbert Simon uses to refer to those who engage in problem-solving, whatever professional discipline they had been trained in. In that context, the term is used for people whether or not they belong to "hard" professions, such as medicine, law, architecture, or accounting. I don't think that the shift from "public managers" to "professional practitioners" does violence to Moore's theory, even if all of the case studies in his book are about people whose roles matched the definitional properties of public managers.

I may be taking an extreme view, but I think that the idea of public managers in Moore's book was more an expository device than anything else. It made the discussion more concrete; it made the messages, and even some arguments, sticky. It was a powerful expository device: but it has gotten in the way of understanding his argument.

By way of summary, let's try to visualize Moore's purposive theory of public management as a professional practice, with the aid of Figure 2.1. As you can see, the main elements of the diagram are (a) a purposive theory of public 


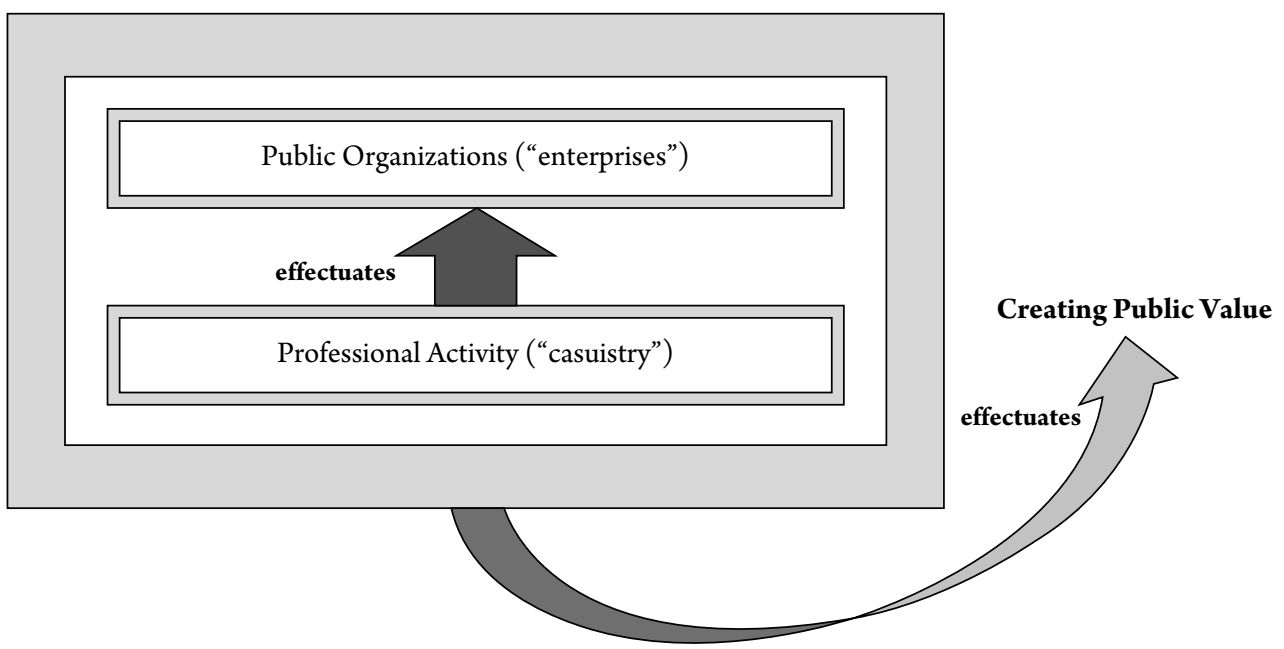

Figure 2.1 A model of Moore's purposive theory of public management as a professional practice

organizations and (b) a purposive theory of professional activity in relation to public organizations. I include the reference to "enterprises" in the upper rectangle to remind you that the term "public organizations" in Moore's text covers (a) public service operations and the programs they deliver, as well as (b) performance of public organizations' management function.

Let me now explain the arrows. One feature of Moore's theory of public management is that professional activity is theorized as being oriented to fulfilling public organizations' purposes, while another feature is that the purposive nature of public organizations is to effectuate public value creation. By compressing these two thoughts into one, you get the emblematic code-phrase that "public managers create public value." Accordingly, I put public organizations and professional activity together in a single box - for professional practice in public management - and then present both public organizations and professional activity as effectuating public value creation. This way, the structure of the theory is preserved, while aligning its presentation with the book's stickiest idea.

If you've read Moore's book, you might be wondering why I so far haven't dealt much, or at all, with many of the ideas that might have stuck with you, as in the case of the strategic triangle diagram, with the terms, value, support, and capacity, placed in one or another of its corners. The reason is that I've showcased the background or "meta" argument of Moore's book. The excuse is that, in my experience, you won't understand these sticky ideas, unless you have already learned how to fit them within Moore's overall purposive theory of public management; and, further, I submit that you won't be able to do that, unless you appreciate where the ideas came from.

You will see more of the "foreground" argument of Moore's theory of public management in Chapter 4. However, there's an important piece of unfinished business to take care of now. And that is to "rediscover" Herbert Simon's ideas as they relate to professional practice in settings that include enterprises like public 
organizations; the rationale for this excursion was explained in this chapter's introduction. Let's now proceed, beginning with the telling of the backstory to Simon's design-oriented theorization of professional practice in the context of organizations.

\section{Discovering the backstory on Simon, design, and management}

In 1949, Herbert Simon left his academic position at Illinois University of Technology in Chicago to join the faculty of the Graduate School of Industrial Administration (GSIA) of Carnegie Institute of Technology (later, CarnegieMellon University), in Pittsburgh, Pennsylvania. ${ }^{13}$ His own move was part of a larger event. GSIA had also successfully recruited promising economists from the University of Chicago, who had been associated with its Cowles Commission for Research in Economics (as indeed Simon had been). The influx was due to GSIA's having signed up to embody and implement a new - "modern" approach to the management discipline. The approach was positioned against two existing ones: a trade-school approach found on the undergraduate level in many universities, and the Harvard Business School approach at the graduate level. The "modern" approach to the management discipline was conceived and presented as being more scientific than its predecessors. A more specific, central idea was that management practice would come to derive from fundamental knowledge, scientifically discovered, by the sort of researchers GSIA was to appoint as faculty. Thus, Simon was present at the creation of a true modern management school.

The modern management school idea was deliberately constructed. A key source of the idea was the so-called modern medical school. This approach to the medicine discipline was embodied by Johns Hopkins University, in Baltimore, Maryland, considered to have been among the first research universities (on the German model) in the United States, along with the University of Chicago. Under the modern medical school, faculty would be recruited and promoted for their scientific research promise and achievements, while medical students would devote most of their first two years of study to acquiring medicine's fundamental scientific knowledge. Part of the idea was that a modern medical school would be good for the practice of medicine: medical advances would flow from medical research conducted scientifically; young doctors would be schooled in the most advanced medical knowledge and practices; and medical practice would inevitably improve as a result. These ideas had been developed around 1910, with support from the Ford Foundation. Beginning in the late 1940s, the same foundation encouraged using the modern medical school as a precedent for theorizing the management discipline and developing business schools along lines that resembled it.

Simon's relationship to GSIA and the modern management school was different from that of economist colleagues who had come there from the Cowles Commission. Simon did his doctorate in political science, working within the field of public administration, at the University of Chicago. During the depths of the Great Depression and during much of World War II, Simon worked in 
institutions that did practical public administration research, first in Chicago and then at the University of California, Berkeley. By the time he moved to GSIA from Illinois University of Technology, Simon had published "The proverbs of administration" in Public Administration Review, ${ }^{14}$ and had completed what was later the first edition of Administrative Behavior. ${ }^{15}$

Simon's views on the management discipline were compatible with those of his GSIA colleagues in a number of regards. By looking back to "Proverbs of administration," you can suppose why. In that article, Simon sought to discredit the practical value of what he called classical administrative theory. In a line that stole the show, Simon stated that a fundamental problem with classical administrative theory is that it lacked theory. Simon critiqued classical administrative theory as peculiarly detached from properly theorized empirical realities of organizational phenomena, such as the way in which expertise channels decision-making, typically even more so than formal authority does. Simon complemented this critique of classical administrative theory by presenting an approach to diagnosing administrative problems, which he called administrative analysis. Simon indicated a direction for developing better theory that could be used for such analysis. This was the direction that he followed in developing organization theory along the lines of decision-making. So, for Simon, it was important to develop fundamental knowledge of organizations in order for both public administration and management to be disciplines worthy of the name.

The importance of developing fundamental knowledge for the management discipline was an idea Simon shared with his GSIA colleagues. Nevertheless, there was a difference in view. Simon's picture of management practice was different from that of using theory-based tools in making decisions about matters to do with a single functional area of management, like finance or marketing. His picture of management was closer to what was done by organizations in effectuating major accomplishments in the life of an organization or nation. From the standpoint of the 1950s, a recent case-in-point was the Manhattan Project, which had drawn together vast national resources and organized the U.S. effort to develop atomic weapons. The Manhattan Project later became a model for other organized efforts to develop solutions to major problems - in particular, for efforts organized by the RAND Corporation. Simon had firsthand experience with RAND projects in the national security field. A hallmark of such projects was that they involved people whose domains of expertise were dissimilar. From this perspective, management involves problem-solving, where problem-solving requires coordinating activity so that multiple domains of knowledge are brought to bear. That is a different perspective on the practice of management than applying theory-based tools in making decisions within a domain of an organization.

Pulling the threads of this story together, we can see that for Simon, professional practice in managing looks somewhat similar to creating artificial systems (including but not limited to those of a physical or digital character). The aspect of creating artificial systems of greatest relevance to management was organizing such efforts and (thereby) enabling the activities of analysis, synthesis, testing, evaluation, and decision-making. If management students were going to be able 
to contribute to this, they would have to know something about organizing, decision-making, and designing.

This seems like an important backstory to Sciences of the Artificial. That volume first came out in 1969, some years after Simon parted company with GSIA colleagues and became based in other parts of Carnegie-Mellon University, specifically its departments of psychology and computer science. In a way, he wanted engineers to be taught not only how to do the work of analysis and design of artificial systems (important as this was), but how to "manage" problem-solving, as well. What he wanted managers to be taught was not just how to make decisions within an organization's functional domains, but how to manage problemsolving, including in settings where the challenge is to create novel artificial systems, including those of a physical and digital character.

In Simon's purposive theory of artificial-system creation, the mechanism for creating artificial systems is a project. Just to accentuate its specific association with creating artificial systems, let's label this idea as a "design-project." At the point where a design-project is complete, systems are not yet in production, or operational. Design-projects are constituted by several functions: specifically, analysis, synthesis, testing, and evaluation (see Figure 2.2).

Figure 2.2 visualizes Simon's purposive theory of design-projects as a conceptual hierarchy. The functional elements of design-projects are represented by the five boxes arrayed along the hierarchy's base. Saying that these boxes represent functional elements means that each function needs to be performed to an adequate extent in effectuating a design-project's intent. The functions are evidently differentiated. The outcome of analyzing problems is a problem-structure and solution-structure; the outcome of synthesizing solutions is designs for artificial systems; the outcome of testing and evaluating solutions is information about the fit between the behavior of an artificial system and its intent. The outcome of evaluating alternatives is information about the relative merits of solutions that have eventuated from the upstream functions within design-projects. The outcome of selecting alternatives is a commitment to proceed with the downstream

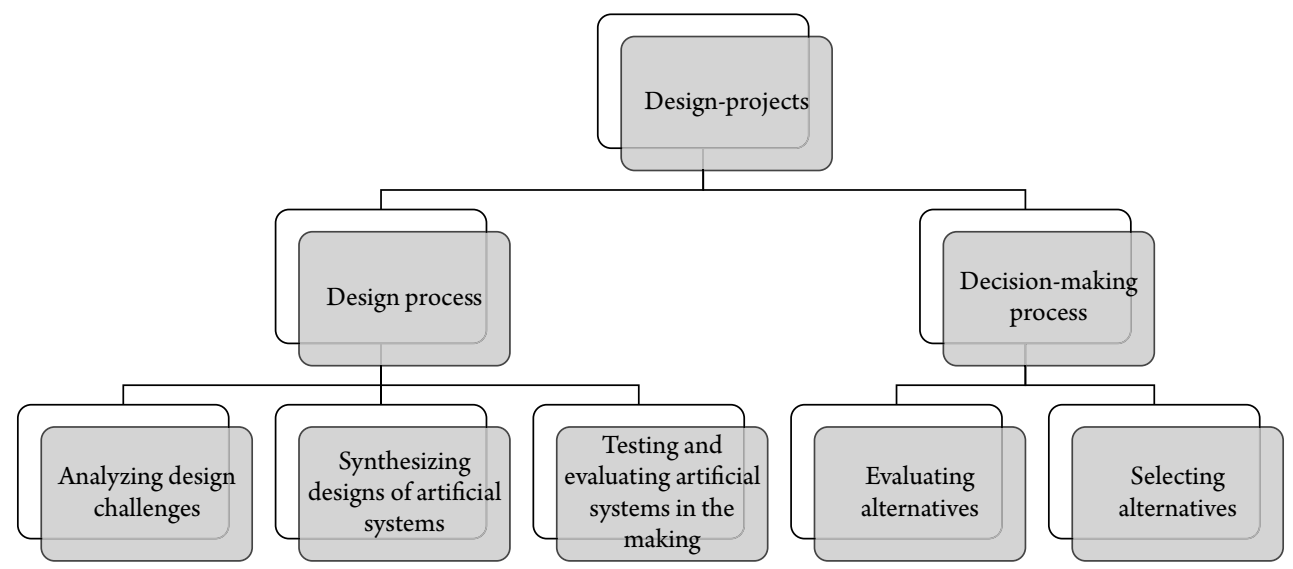

Figure 2.2 Visualizing Simon's theory of design-projects 
realization of the artificial system that was designed upstream. The functional elements are not only differentiated; they are interdependent. Without synthesizing designs for artificial systems, there's nothing to test and evaluate. Without analyzing design challenges, there's not enough structure to a problem or solution for design synthesis. And so on.

Relative to these functional elements of design-projects, the middle level of the hierarchy is a higher-level break-down, consisting in the design process and decision-making process. Grouping the elemental functions in this way makes the point that the creation of novelty within enterprises and their organizations depends, in part, on performing functions that do not fall within Simon's concept of decision-making. Specifically, the creation of novelty depends on performing the function of design synthesis, which falls within Simon's concept of the design process. Stepping back from these details, the idea is that designprojects involve decision-making and designing as distinct, but interdependent functions, with their corresponding processes.

Chapter 5 of Sciences of the Artificial, when twinned with that volume's first chapter, promotes the idea that creation of novelty - specifically in respect to artificial systems - is critically important to organizations. That stance underwrites the importance of design-projects within organizations. Pushing the idea of design-projects, in turn, positions "designing" as an intrinsically important aspect of organizations. That is the take-away that has been picked up by a variety of fields of management, including information systems.

Taking into consideration the history of business schools recounted the outset of the present chapter, Simon's Chapter 5 can be seen as a bid to reformulate purposive theories of management. In particular, it represents an attack on dominant ideas within the modern management school, which were drawn from the modern medical school. Creating novelty in artificial systems was not a central issue for mainstream thinking within the modern management school. The mainstream of the modern management school was focused on creating fundamental knowledge about finance, marketing, and operations and translating such knowledge into tools to be used by managers skilled in their use as they make decisions within organizations. Accordingly, designprojects - and the sort of problem-solving they effectuate - were not of great interest or concern. History shows that Simon was keen to establish his contrasting ideas about management within the modern management school, to which he belonged when serving as a professor at Carnegie's Graduate School of Industrial Administration.

However, what this historical account doesn't elucidate is the relevance of the idea of design-projects for the Harvard version of the professional discipline of management. Within that tradition - a predecessor and rival to the modern management school - decision-making was theorized as a mechanism for performing the management function within enterprises (a perspective that was reinforced as HBS responded to its rival, around 1960). Management continued to be theorized as a judgmental process that is improvable through simulated experience with administrative situations, whereby students present rationales for specific choices and courses of action, in the face of critique through instruction. 
Figure 2.3 Visualizing the Harvard tradition of purposive theorizing of enterprises and their management

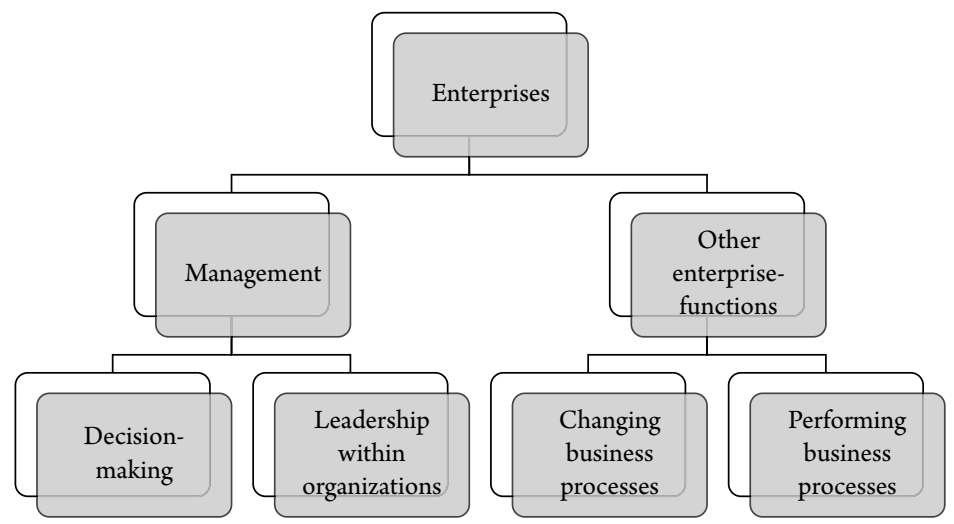

In addition, management was theorized as constituted by bringing about the adoption of decisions within an organization and the setting in motion of their follow-through, via what might be broadly labeled as leadership within organizations.

Figure 2.3 places these ideas in a scheme that situates the Harvard tradition within Fayol's purposive theory of enterprises. As discussed in Chapter 1, Fayol's theory held that the effectuation of enterprise-intent requires the performance of six enterprise-functions, namely, accounting, commercial, finance, management, security, and technical, in alphabetical order. The figure above groups all the enterprise-functions apart from management on the right hand-side. These enterprise-functions are depicted as being similar in that they are performed by businesses processes; in recognition of the fact that business processes undergo change in order to be adequate to their functions, an additional element is added, namely, "changing business processes."

Now let's consider Simon's Chapter 5 in relation to this Harvard-esque scheme. If we stick with the idea that design-projects are for creating novel artificial systems, then we should place design-projects squarely within the box for "changing business processes," on the basis that business processes are typically performed through use of artificial systems. However, we can take Simon's Chapter 5 to be relevant to the enterprise-function of management, as well, by seeing Simon as challenging the idea that management is decision-making plus leadership. Management itself involves designing, by this argument - even if management also involves decision-making and leadership. This interpretation is fair, as Simon published on creativity, an idea tied to design synthesis, but is not specific to creating novel artificial systems.

We can think of Simon's Chapter 5, having arisen as a strong dissent from the modern management school to which Simon institutionally belonged, as being a friendly amendment to the Harvard tradition, from which he was institutionally distant. To reiterate, this amendment involves seeing the enterprise-function of management as performed by the function of design synthesis, enabled by analysis of design challenges. An auxiliary amendment is that design-projects - with their interlocking design and decision-making processes - are mechanisms for performing the enterprise-function of management. This point is an amend- 
ment of the Harvard tradition as its stereotypical mechanism for performing the enterprise-function of management is what individual managers do within organizational settings. Design-projects are not theorized in this way: they are collective organizational phenomena. To think of design-projects in this way, this concept has to be reformulated to the extent that they are seen to create novelty in any form of purposeful phenomena within organizations, not just artificial (technical) systems. Plans and organizational arrangements are examples of the kind of novel, purposeful phenomena that eventuate from design-projects but don't fit the category of artificial systems. In sum, we can consider placing ideas that relate to design-projects, like design synthesis, as well as the idea of a design-project itself, inside an updated mainstream version of the Harvard tradition. If we do so, then we will recognize Simon's gift to the Harvard tradition of theorizing management.

\section{Structuring design-oriented purposive theories of management and public management}

I would now like to follow through on this line of thinking, to the point of formulating a design-oriented purposive theory of enterprises and their management, by unifying the Harvard tradition, on the one hand, with Simon's ideas about designing, decision-making, and design-projects, on the other. Among other things, doing so will elucidate the meaning of the book title, Public Management as a Design-Oriented Professional Discipline. In particular, it elucidates the idea of professional knowledge within this discipline, by pointing to the conceptual structure and origins of its intellectual foundation. Put directly, the unified Harvard-Simon conception of enterprises and their management constitutes the underlying intellectual foundation of professional knowledge within the professional discipline of public management, as it is constructed in this book. The adjective "design-oriented" is meant to dramatize this synthesis between the Harvard tradition and Simon's stance in Sciences of the Artificial. I will now present the synthesis, with the aid of Figure 2.4 , and then move on to discuss it more fully, as a prelude to the rest of this book.

The official label for Figure 2.4 is "Fundamentals of design-oriented theories of enterprises and their management." That label is accurate, especially as it is faithful to Henri Fayol's theory of enterprises. While accurate, the label is unfortunately forgettable. To overcome this problem, we can refer to Figure 2.4 as the "the sandwich diagram" or "the SD," for short.

Let me walk you through the SD to pinpoint what it consists in. The top slice is concerned with enterprises in their totality and their constitutive functions. The bottom slice is concerned with the activities in which professional practitioners, including those labeled as managers, engage as they work within enterprise-organizations. The slice in the middle is concerned with design-projects and their constitutive processes of designing and decision-making. Each slice consists in a two-level conceptual hierarchy. Enterprise-functions are constitutive of enterprises, while the design process and the decision-making process are constitutive of design-projects. As for professional activities, the subordinate 


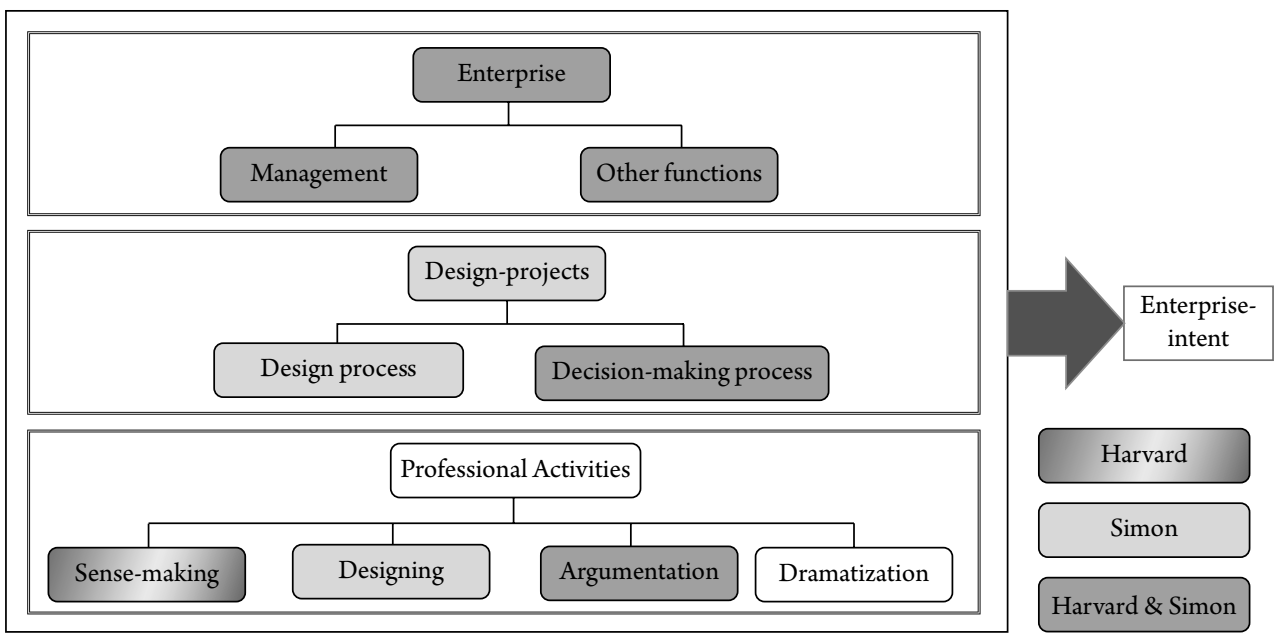

Figure 2.4 Fundamentals of design-oriented theories of enterprises and their management - the sandwich diagram

level elements are forms of professional activity, rather than a full set of constitutive functions.

I want to now make absolutely clear how this scheme relates to its origins. The top slice is due to Fayol's theory of enterprises, in which enterprise-intent is effectuated by performing six enterprise-functions, of which management is one. Fayol's theory runs through the Harvard tradition; in fact, one of the most famous conceptual schemes in that tradition - Porter's value-chain ${ }^{16}-$ can be traced back to it. For his part, Simon didn't reference Fayol's theory of enterprises; indeed, his best-known early publication ${ }^{17}$ was scathing in its critique of ideas about organizations that drew from Fayol's theory. Nevertheless, Simon's theorization of design-projects presumed that they were conducted within organizations and that those organizations effectuate enterprise-intent. For these reasons, I have coded all the elements of the top slice as originating from both Harvard and Simon.

The middle slice is due to Simon's theory of design-projects. However, that theory overlapped with the Harvard tradition, which came to theorize decisionmaking as the way in which the enterprise-function of management is performed within organizations. Thus, what's specifically tied to Simon's theory of designprojects is two ideas. One is the idea of design-projects itself, as an organizational mechanism for performing enterprise-functions. The other is the idea of the design process, with its constitutive functions of analyzing design challenges, synthesizing designs, and testing and evaluating designs. For these reasons, I have coded "design-projects" and "design process" as originating with Simon and "decision-making process" as originating from both Harvard and Simon.

As mentioned, the bottom slice theorizes what professional practitioners do when working within enterprises and their organizations. The Harvard tradition's pedagogy is known for emphasizing what I call the professional activities of sense-making and argumentation. They are integral to this tradition because 
managers have been depicted to play the role of making decisions in the face of circumstances that pose challenges to effectuating enterprise-intent. The Harvard theory of making decisions has origins in casuistry, as argued earlier. Casuistry consists in making sense of situational circumstances as they relate to a community's moral principles, deliberating about the proper course of action through the exercise of judgment, and providing an explicit rationale for the resulting decision through the exercise of the ability to formulate and state a sound practical argument. Accordingly, the ideas of "sense-making" and "argumentation" trace back to the Harvard tradition.

If you think about Simon's take on what professional practitioners do within enterprises and their organizations, you need to grasp the idea of designing. Don't be confused by the term "designing" showing up in the bottom slice, while the term "design-process" shows up in the middle slice. Designing is the profile of activity done by individuals in a dynamically stable context within an enterprise, a context that specifically includes a design-project in which numerous individuals participate. The designing/design-process distinction is just like the distinction within organization theory between thinking and communicating, on the one hand, and the decision-making process, on the other. As to what designing consists in as an activity, that's a long story: it's not particularly detailed in Simon's Sciences of the Artificial, as his main point is that professional practitioners need to learn to design, through forms of education that simulate experience, much as takes place in studio classes within professional training in architecture. For our immediate purposes, we can recognize, first, that "designing" is a form of professional activity within a design-oriented theory of enterprises and their management and that, second, this idea originates with Simon's Sciences of the Artificial.

Anything else said about the sandwich diagram's bottom slice is more footnote than main text. I'll make three such points. First, the idea of argumentation stems from both Harvard and Simon. For Simon, argumentation is something that professional practitioners do when participating in either the decisionmaking or design processes. Argumentation is part of communication within decision-making, and the same is true for communication in performing the analysis of design challenges and the testing and evaluation functions within design processes. (It's not true of synthesizing designs.) For this reason, argumentation is coded as Harvard and Simon. Second, I code "sense-making" as Harvard rather than Harvard and Simon, because this idea is much more explicit within the Harvard tradition, because of its connection with casuistry, than in Simon.

Third, I've introduced two concepts - professional activities and dramatization - that are intrinsic to the design-oriented theory of enterprises and their management but are not prominent bits of the vocabulary of either Simon or Harvard. Accordingly, both are left "uncoded" in the sandwich diagram. The term "professional activities" does no more than serve as umbrella term for all the items that are listed underneath it, a list that can be expanded to include other ideas like deliberation as well as another subordinate level of concepts. This term is more suitable than either "practices" or "skills." It's more suitable than "practices" 
because within a discussion of enterprises and organizations, the idea of practices connotes patterns of activity that have a basis in the organization itself. It's more suitable than "skills" because these professional activities, while skillful, are inherently social or interactive, whereas the idea of skills connotes dexterity in manipulating data, information, or other substances. The other reason to take care in labeling this collection of activities is that the idea of "skill" is more strongly linked to the modern management school than to the Harvard tradition: in the former, skill is what an individual does in using theory-based tools to reach a conclusion on what decision is optimal for performing an enterprise-function under particular conditions. Thus, I wish to downplay the vocabulary of skill, as the design-oriented theory here is taken to be a synthesis of Simon and Harvard, not of Simon and the modern management school.

Turning to "dramatization," this term is drawn from the work of Erving Goffman, the venerable north American sociologist who famously theorized social action and situations as if they are on-stage performances that sit alongside back-stage interactions among individuals who form teams. His famous book was The Presentation of Self in Everyday Life. ${ }^{18}$ The idea belongs here for a couple of reasons. Dramatization refers to a professional ability that is cultivated through practice and instruction within the Harvard tradition. In that classroom, you need to be good at dramatizing both your arguments and yourself to earn a superior mark. Furthermore, we can see dramatization as contributing to a theory of leadership within organizations, an idea that helps to broaden out the Harvard tradition from its casuistical base, which is concerned with decisionmaking specifically and narrowly.

Now that I've taken you through a discussion of what the sandwich diagram consists in, let me remind you of what it is for. It is for creating a theory of enterprises and their management, one that distances itself from the modern management school, while improving the Harvard tradition. (Note: In my judgment, Simon can be used only to reformulate either the modern management school or the Harvard tradition: it doesn't have the historical heft or internal constitution to carry off being a theory of enterprises and their management, on its own - a point I come back to in Chapter 8.)

\section{Conclusion}

I have worked you through this long background argument for reasons having to do with the architectonics of this book on public management as a designoriented professional discipline. One reason is that if public management is to be a professional discipline (an argument with reasons of its own), public management needs to expand and teach professional knowledge about public organizations and professional practice. If it is going to do that, then it needs to build up a purposive theory of public organizations and professional practice within them. A good precedent and point of departure for doing so is Moore's Creating Public Value: Strategic Management in Government, for reasons discussed earlier in this chapter and in the last one. However, there are issues to consider in choosing to make Moore's book a foundational work for purposive theorizing of public 
management. The issues arise because Moore's book thoroughly reflects the Harvard tradition, while the Harvard tradition has limitations even in the view of its sympathizers and adherents, like me. In my mind, the most effective way to set out reservations about the Harvard tradition - and to point toward ways of overcoming them - is to do the background work of synthesizing Harvard and Simon, to form the outlines and basic vocabulary of a design-oriented purposive theory of enterprises and professional practice within them.

This book shows a way to build up professional knowledge about public management, while providing something of an installed base of such knowledge itself. You will soon see how I draw on a variety of otherwise isolated works to create this base, when you get to Chapter 4, which is divided into sections about public organizations, design-projects, and professional activities. However, as a prior step, you're invited to listen in on a conversation about this aspect of public management as a design-oriented professional discipline, where Marshall is trying to bring along Nora, Olivier, and Petra, to a place where they can take it all in.

\section{NOTES}

1 Augier and March (2011).

2 Lynn (1996).

3 Simon (1996).

4 Van Aken (2004).

5 Moore (1995).

6 A precedent for using the word "effectuate" in this way is Sarasvathy (2008).

7 This statement is a case of "context channels activity, which eventuates in outcomes," which I take to be the conceptual structure of scenarios. See Chapter 3.

8 The background reference to this statement is Fauconnier and Turner (2002).

9 Texts like Moore's are not usually, if ever, presented as well-structured, purposive theories - for understandable reasons, considering their audiences. But suppose that this was something to be done. Formulating, or re-constructing, such theories in a structured way requires using tools of interpretation and some standards of presentation. Such tools and standards would constitute a patterned-language for theorizing purposeful phenomena. Use of such a patterned-language would enable a professional discipline's development. Statements like ones enumerated above exhibit such a patterned-language. More will be said along these lines as we progress.

10 Fayol (1919/1984).

11 Augier and March (2011: 152).

12 Jonsen and Toulmin (1988).

13 This section is based primarily on Augier and March (2011).

14 Simon (1946).

15 Simon $(1947 / 1968)$.

16 Porter (1985).

17 Simon (1946).

18 Goffman (1959). 